Proceedings

\title{
Mussels Based Food Supplements: Evaluation of Emerging Ma- rine Toxins is a Necessary Evil
}

\author{
Paz Otero *, Carmen Vale, Andrea Boente-Juncal, Celia Costas, M. Carmen Louzao and Luis M. Botana
}

Citation: Otero, P.; Vale, C.; BoenteJuncal, A.; Costas, C.; Louzao, M.C.; Botana, L.M. Mussels Based Food Supplements: Evaluation of Emerging Marine Toxins is a Necessary Evil. Proceedings 2021, 65, $\mathrm{x}$. https://doi.org/10.3390/xxxxx

Received: 20 October 2020 Accepted: 21 December 2020 Published: 14 January 2021

Publisher's Note: MDPI stays neutral with regard to jurisdictional claims in published maps and institutional affiliations.

Copyright: (c) 2021 by the authors. Submitted for possible open access publication under the terms and conditions of the Creative Commons Attribution (CC BY) license (http://creativecommons.org/licenses /by/4.0/).
Departament de Farmacología, Facultad de Veterinaria, Universidad de Santiago de Compostela, 27002 Lugo, Spain; mdelcarmen.vale@usc.es (C.V.); andrea.boente.juncal@usc.es (A.B.-J.); celia.costas.sanchez@usc.es (C.C.); mcarmen.louzao@usc.es (M.C.L.); luis.botana@usc.es (L.M.B.)

* Correspondence: paz.otero@usc.es

\begin{abstract}
Food supplements containing mussel extracts are becoming popular in human diet, providing high levels of proteins, omega-3 polyunsaturated fatty acid (PUFAs), iodine and carbohydrates. Besides the beneficial effects and bioactives that mussel may yield, it is vital to consider the potential harmful phycotoxins that can be present in mussel extracts and marine dietary supplements. Recently, we have detected for the first time the marine toxin 13-desmethyl spirolide $\mathrm{C}$ in food supplements containing green lipped mussels of Perna canaliculus at levels up to $98 \mu \mathrm{g} / \mathrm{kg}$. In this work, we provide new data about the presence of pinnatoxin-G (trace amounts) in the dietary supplements intended for human consumption after the analysis of the green lipped mussel powder by UPLC-MS/MS. Moreover, the status of microalgae phycotoxin contaminants is also assessed in these products and in animal dietary supplements which contained 13-desmethyl spirolide $C$ at levels up to $39 \mu \mathrm{g} / \mathrm{kg}$. The mechanism of action of spirolides and pinnatoxins is associated with the blockage of the muscarinic and nicotinic receptors (mAChR and $\mathrm{nAChR}$ ) on the nervous system. Despite the fact that human intoxications have not been reported, it is important to identify the impact of such toxins on public health since dietary products constitute an important part of the global market.
\end{abstract}

Keywords: lipophilic toxins; 13-desmethyl spirolide C; pinnatoxin-G; dietary supplements; Perna canaliculus; UPLC-MS/MS.

\section{Introduccion}

Marine food supplements constitute an important part of the worldwide market. They are produced from different matrix, providing a large number of bioactive molecules like proteins, omega- 3 fatty acids, vitamins, minerals, carotenoids and polysaccharides [1-3]. Especially, green lipped mussels' powder is sold for their benefits in the treatment of osteoarthritis [4]. This product has hight anti-inflammatory activity due to the polyunsaturated fatty acids profile [5]. Despite they are announced as beneficial for health, food supplements could also lead to potential toxic risks related to the contamination by toxins [6].

In this study, we investigate the presence of lipophilic marine toxins in dietary supplements of Perna canaliculus from New Zealand but commercialized in Europe. Due to the increase of emerging toxin detection worldwide, it is convenient to study the contamination level of marine food supplements. These products are legislated as foods and therefore, it is necessary to guarantee the safety derived from their consumption [7]. Moreover, food supplements are not subjected to pharmacovigilance as is the case with drugs, so the homogeneity among batches is not guaranteed [8].

\section{Material and Methods}




\subsection{Samples Acquisiton}

Green lipped mussels' powder ( $P$. canaliculus) supplements were obtained by 3 different European Union (EU) distributors at random. Once in the laboratory, food supplement capsules were opened, and the powder content was passed to a $45 \mathrm{~mL}$ empty tube. Each sample was a homogenate of 40 capsules content ( $20 \mathrm{~g}$ approx.). 6 samples were sold for human consumption and 3 of them were labelled as dietary supplements for dogs (Table 1). Each capsule has $500 \mathrm{mg}$ of concentrated green mussel.

Table 1. Dietary samples for human and animal consumption.

\begin{tabular}{cc}
\hline Food Product & No. of samples \\
\hline Dietary supplements (Green lipped mussels) for human & 6 \\
Dietary supplements (Green lipped mussels) for animals (dogs) & 3 \\
\hline
\end{tabular}

\subsection{Toxin Extraction}

Food supplements were extracted adding methanol after their rehydration. First an amount of $1.64 \mathrm{~mL}$ of water was added to $0.36 \mathrm{~g}$ of power food supplement in order to have a humid mussel extract with the same water content as the fresh mollusc $(82 \pm 0.02 \mathrm{~g}$ $\mathrm{H} 2 \mathrm{O} / 100 \mathrm{~g}$. After that, it was extracted according to the standard operation procedure (SOP) for the determination of lipophilic toxins in shellfish. The amount of 2 grams of food supplement homogenate were extracted with $9 \mathrm{~mL}$ of methanol. The extract was homogenized via vortex and then, the samples were centrifuged $(3700 \mathrm{rpm} \times 10 \mathrm{~min}$ ). The content was transferred to $20 \mathrm{~mL}$ volumetric flash. The extraction of the residual tissue pellet was repeated with another $9 \mathrm{~mL}$ of methanol. After centrifugation $(3700 \mathrm{rpm} \times 10 \mathrm{~min})$, the supernatants were combined into a final volume of $20 \mathrm{~mL}$ with methanol. The volume of $15 \mathrm{~mL}$ was concentrated to $5 \mathrm{~mL}$ to improve the sensitivity of the analyses. One aliquot of $500 \mu \mathrm{L}$ was filtered through $0.22 \mu \mathrm{m}$ filter and then analysed by UPLC-MS/MS.

\subsection{UPLC-MS Analysis}

Analyses were performed by a 1290 Infinity ultra-high-performance liquid chromatography system coupled to an Agilent G6460C Triple Quadrupole mass spectrometer equipped with an Agilent Jet Stream ESI source (Agilent Technologies, Waldbronn, Germany). The toxins were separated using a column AQUITY UPLC BEH C18 $(2.1 \times 100 \mathrm{~mm}$, $1.7 \mu \mathrm{m}$, Waters) at $40{ }^{\circ} \mathrm{C}$. Mobile phase A was $100 \%$ water and B acetonitrile-water (95:5), both containing $50 \mathrm{mM}$ formic acid and $2 \mathrm{mM}$ ammonium formate. The gradient program with a flow rate of $0.4 \mathrm{~mL} / \mathrm{min}$ was started with $30 \% \mathrm{~B}$ and then a linear gradient to $70 \%$ $\mathrm{B}$ in $3 \mathrm{~min}$. After an isocratic hold time linear of $1.5 \mathrm{~min}$ at $70 \% \mathrm{~B}$ and return to the starting conditions of $30 \%$ B in $0.1 \mathrm{~min}$. Finally, 30\% B was kept for $1.99 \mathrm{~min}$ before the next injection. The samples in the autosampler were cooled to $4{ }^{\circ} \mathrm{C}$ and the injection volume was 5 $\mu \mathrm{L}$. Source conditions were: $350^{\circ} \mathrm{C}$ of drying gas temperature with $8 \mathrm{~L} / \mathrm{min}$ flow, nebulizer gas pressure of $45 \mathrm{psi}$ (Nitrocraft NCLC/MS from Air Liquid, Madrid, Spain), sheath gas temperature of $400{ }^{\circ} \mathrm{C}$ and a flow of $11 \mathrm{~L} / \mathrm{min}$. The capillary voltage was set to $4000 \mathrm{~V}$ in negative mode with a nozzle voltage of $0 \mathrm{~V}$ and $3500 \mathrm{~V}$ in positive mode with a nozzle voltage of $500 \mathrm{~V}$. Analysis were performed in multiple reaction monitoring (MRM) acquisition mode, selecting two transitions per molecule. The MS/MS transitions for the screening of lipophilic toxins were previously described [9]. Certified reference materials were provided by Cifga (Lugo, Spain) and The Institute for Marine Biosciences, National Research Council, Halifax, NS, Canada.

\section{Results}

Chromatograms of dietary supplements of $P$. canaliculus showed the existence of two peaks in the minute 2.8 and minute 3 . Figure 1 represent the total ion chromatogram of a sample intended for human consumption. 


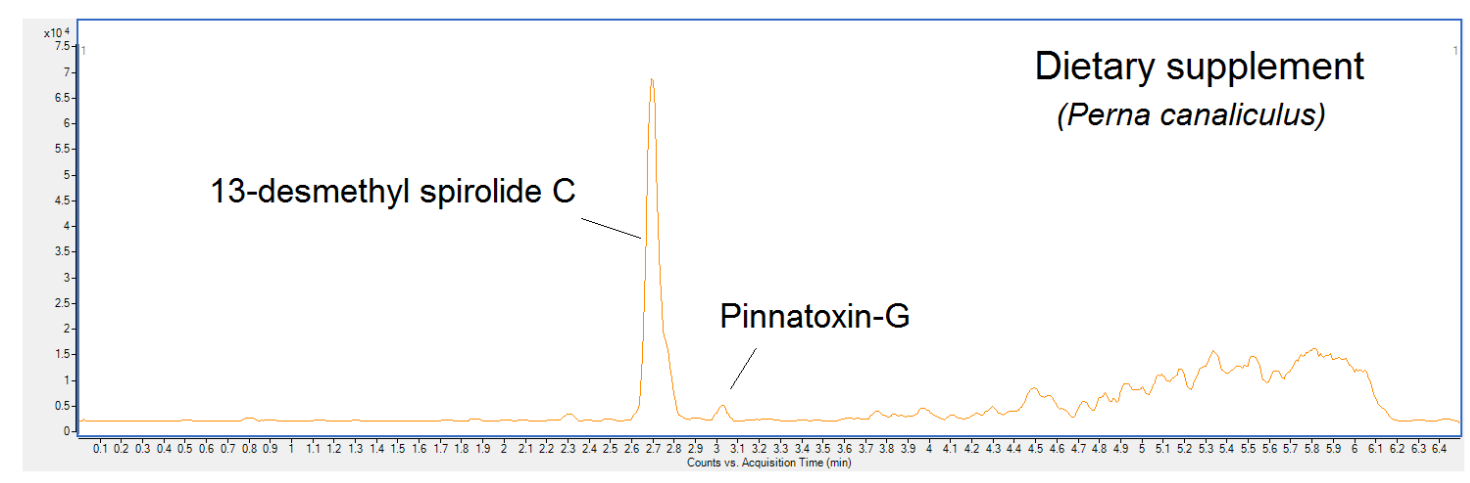

Figure 1. Total ion chromatogram (TIC) of dietary supplements (Green lipped mussels) for humans.

Analysing theses peaks by multiple reaction monitoring (MRM) mode and using two transitions per molecule, it was observed that the first peak correspond to 13-desmethyl spirolide C (Figure 2) at levels around $90 \mu \mathrm{g} / \mathrm{kg}$ (dry product) and the second peak is pinnatoxin G (Figure 3) in trace amounts. These analyses confirm the presence of PnTXs in dietary supplements of $P$. canalicus. The maximum level of 13-desmethyl spirolide $C$ in these supplements was $98 \mu \mathrm{g} / \mathrm{kg}$. Both toxins belong to the cyclic imine $(\mathrm{CI})$ group, toxins which are not under legislation.

13-desmethyl spirolide $C$ was quantified by an external standard calibration and considering the matrix effect which were calculated using matrix in the absence of toxins as a blank sample. There was a negative effect which entailed a suppression of signal $(-2.5 \%)$. Linearity was assessed by calibration curves (nine points) prepared in both methanol and matrix within the range of $0.1 \mathrm{ng} / \mathrm{mL}$ to $25 \mathrm{ng} / \mathrm{mL}$, obtaining a proper adjusted linear regression in both cases $\left(r^{2} \geq 0.998\right)$.

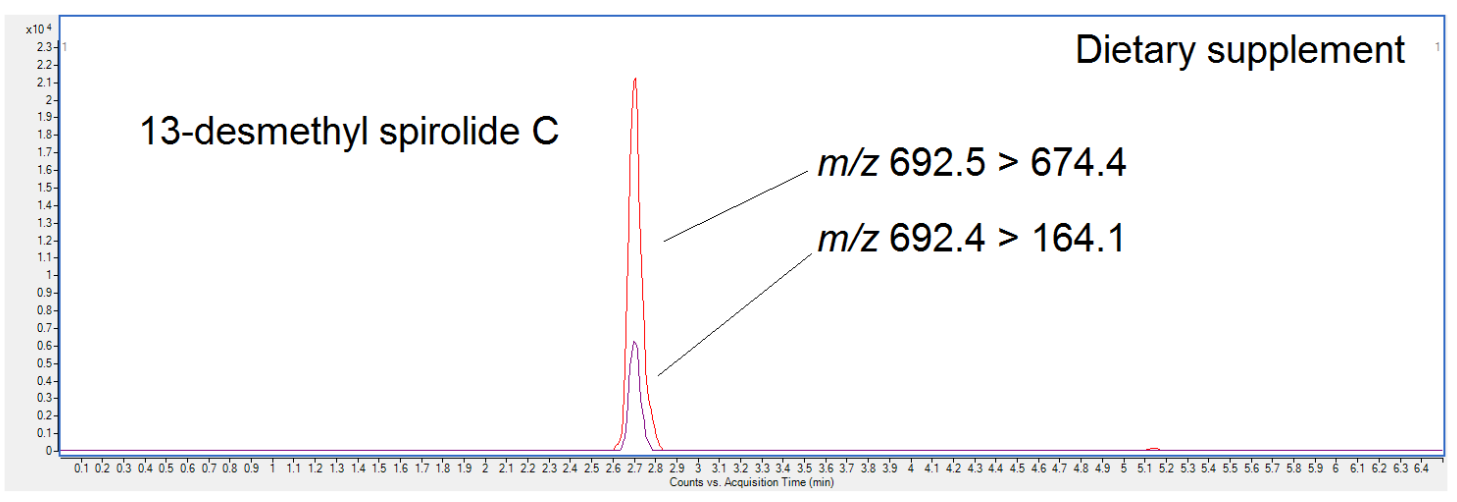

Figure 2. 13-desmethyl spirolide C analysis by Multiple Reaction Monitoring Chromatogram (MRM) from dietary supplements (Green lipped mussels) for humans. 


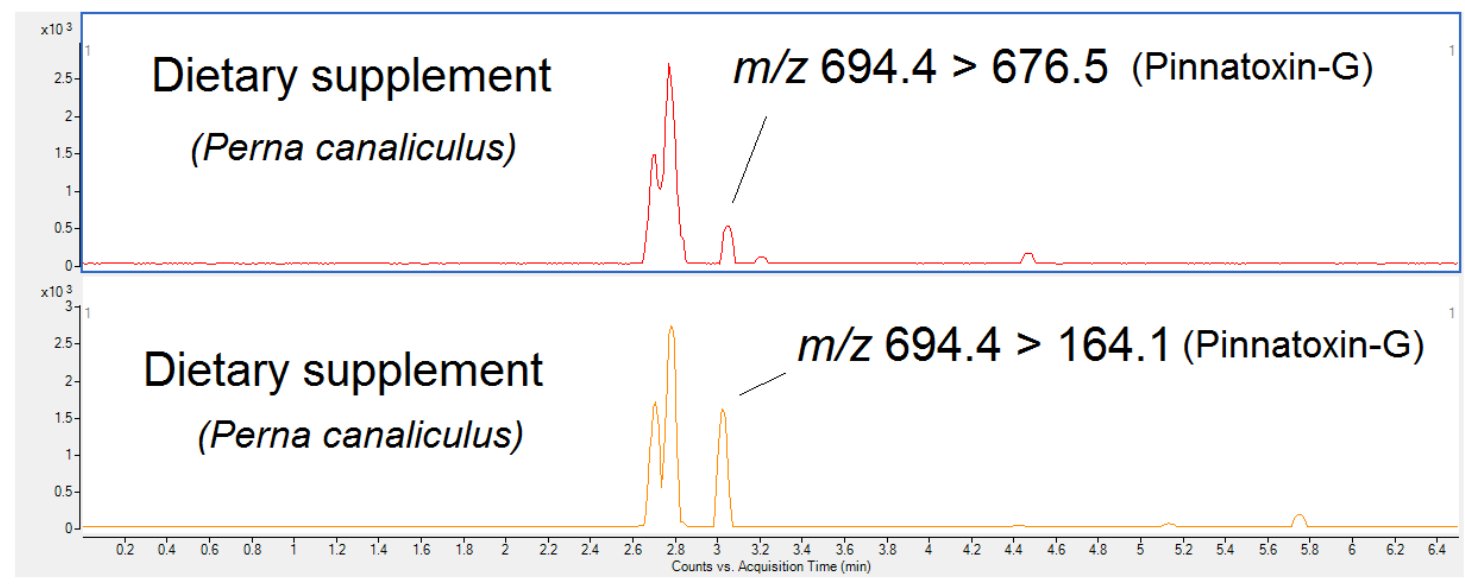

Figure 3. Pinnatoxin-G analysis by Multiple Reaction Monitoring (MRM) (two channels) from dietary supplements (Green lipped mussels) for humans.

Food supplement samples of green lipped mussels for dogs showed just the presence of 13-desmehtyl spirolide C ranging from 33 to $39 \mu \mathrm{g} / \mathrm{kg}$ (dry product).

\section{Conclusions}

Despite the fact that several toxic substances have been recorded in marketed samples of food supplements, these samples constitute the first reported analyses of emerging marine CI toxins in mussel-based supplements. 13-desmethyl spirolide C was found in dietary products intended for both human and animal consumption at levels up to 98 $\mu \mathrm{g} / \mathrm{kg}$ and $39 \mu \mathrm{g} / \mathrm{kg}$, respectively. Besides, pinnatoxin-G was confirmed at trace levels. Moreover, there is no other information regarding the presence of CIs in fresh P. canaliculus.

Acknowledgments: This work was supported by the programme "Juan de la Cierva 2016" from the Spanish Government and the project Interreg AlertoxNet EAPA-317-2016. Paz Otero is recipient of a Postdoctoral Funding (Ref. IJCI-2016-27774).

Conflicts of Interest: The authors declare no conflict of interest

\section{References}

1. Suleria, H.A.R.; Osborne, S.; Masci, P.; Gobe, G. Marine-Based Nutreceuticals: As Innovative Trend in the Food and Supplement Industries. Mar. Drugs 2015, 13, 6336-6351.

2. Otero, P.; Quintana, S.E.; Reglero, G.; Fornari, T.; García-Risco, M.R. Pressurized Liquid Extraction (PLE) as an Innovative Green Technology for the Effective Enrichment of Galician Algae Extracts with High Quality Fatty Acids and Antimicrobial and Antioxidant Properties. Mar. Drugs 2018, 16, 156.

3. Otero, P.; López-Martínez, M.I.; García-Risco, M.R. Application of pressurized liquid extraction (PLE) to obtain bioactive fatty acids and phenols from Laminaria ochroleuca collected in Galicia (NW Spain). J Pharm. Biomed. Anal. 2019, 164, 86-92.

4. Cobb, C.; E. Ernst. Systematic review of a marine nutriceutical supplement in clinical trials for arthritis: The effectiveness of the New Zealand green-lipped mussel Perna canaliculus. Clin. Rheumatology 2006, 25, 275-284.

5. Treschow, A.P.; Hodges, L.D.; Wright, P.F.A.; Wynne, P.M.; Kalafatis, N.; Macrides, T.A. Novel Anti-Inflammatory omega-3 PUFAs From the New Zealand Green-Lipped Mussel, Perna Canaliculus. Comp. Biochem. Physiol. B. Biochem. Mol. Biol. 2007, $147,645-656$.

6. Costa, J.G.; Vidovic, B.; Saraiva, N.; do Céu Costa, M.; Del Favero, G.; Marko, D.; Oliveira, N.G.; Fernandes, A.S. Contaminants: A dark side of food supplements? Free. Radical Research 2019, 53, 1113-1135.

7. Parliament, E. Regulation (EC) No 178/2002 of the European Parliament and of the Council of 28 January 2002 laying down the general principles and requirements of food law, establishing the European Food Safety Authority and laying down procedures in matters of food safety. Official Journal 2002. L 031.

8. Biesterbos, J.W.; Sijm, D.T.; van Dam, R.; Mol, H.G. A Health Risk for Consumers: The Presence of Adulterated Food Supplements in the Netherlands. Food Addit. EContam.: Part A, 2019, 36, 1273-1288.

9. Otero, P.; Vale, C.; Boente-Juncal, A.; Costas, C.; Louzao, M.C.; Botana, L.M. Detection of Cyclic Imine Toxins in Dietary Supplements of Green Lipped Mussels (Perna canaliculus) and in Shellfish Mytilus chilensis. Toxins 2020, 12, 613. 